\title{
COMBINATION OF A NON-PYRETHROID INSECTICIDE AND A REPELLENT: A NEW APPROACH FOR CONTROLLING KNOCKDOWN-RESISTANT MOSQUITOES
}

\author{
CEDRIC PENNETIER, VINCENT CORBEL, AND JEAN-MARC HOUGARD \\ Laboratoire de Lutte contre les Insectes Nuisibles, Institut de Recherche pour le Développement, Montpellier, France; \\ Centre Institut de Recherche pour le Développement du Benin, Cotonou, Bénin
}

\begin{abstract}
Although pyrethroid-treated materials are a promising tool for the prevention and the control of dengue in the tropics, the development of pyrethroid resistance in the main mosquito vector (Aedes aegypti) may negate their use for personal and/or community protection. In that context, the efficacy of a mixture of a repellent (N,N-diethyl toluamide [DEET]) and a non-pyrethroid insecticide (propoxur) was investigated under laboratory conditions against both pyrethroid-susceptible and pyrethroid-resistant mosquitoes with the knockdown resistance $(k d r)$ mutation. The results showed that a combination of propoxur and DEET induced a knockdown effect and mortality as high as deltamethrin (a standard pyrethroid) against the susceptible strain, and significantly higher efficacy against the pyrethroid-resistant strain. This could be explained mainly by the existence of a strong synergistic interaction between DEET and propoxur in mosquitoes. This study constitutes a first step towards an alternative strategy for improving mosquito control in areas with pyrethroid resistance.
\end{abstract}

\section{INTRODUCTION}

Pyrethroid insecticides represent important weapons against pests of both economic and medical importance. They share many properties with dichloro-diphenyltrichloroethane (DDT), including a knock down and killing effect, resulting from action against the sodium channels of the peripheral and central nervous systems. ${ }^{1}$ These products show remarkably high efficacy against insects but relatively low mammalian toxicity and low persistence in the environment. $^{2}$ Since the 1980 s, pyrethroids have been widely used as residual sprays on house walls or on mosquito nets to control insects in the domestic environment. ${ }^{3}$ Among these antivector measures, pyrethroid-treated nets have emerged in recent years as the most promising tool for reducing malaria mortality and morbidity, especially in children less than five years of age in disease-endemic areas in Africa. ${ }^{4}$ Insecticidetreated materials (ITMs), which include plastic sheeting, curtains, hammocks, textiles, combat uniforms, or lids of water tanks, have increased importance in personal and community protection against pests and vectors that transmit malaria, typhus, or dengue. ${ }^{5}$

Unfortunately, the emergence of pyrethroid resistance in most mosquito species of public health importance represents a threat for sustainable vector control programs implemented in the tropics. The difficulties come from the fact that resistance to any pyrethroid generally confers cross-resistance to all others, thus limiting the number of effective alternatives suitable for vector control. The knockdown resistance $(k d r)$ gene, which confers cross- resistance to DDT and pyrethroids, is now widely prevalent in mosquitoes of public health importance. ${ }^{6-9}$ In Anopheles gambiae and Culex quinquefasciatus, the $k d r$ mutation is conferred by a single amino acid change (one or both of the two known sites) in the axonal sodium channel insecticide-binding site, whereas knockdown resistance emerged from four amino acid substitutions in Aedes aegypti. . $^{9,10}$

The impact of the $k d r$ mutation on the efficacy of ITMs has been the subject of numerous studies in Africa the past decade. ${ }^{11-13}$ It has been generally observed that the $k d r$ mutation was not sufficient to render pyrethroid-treated nets ineffective, which would result in a relatively high efficacy of impregnated bed nets in killing resistant mosquitoes, but not repelling them. ${ }^{14,15}$ Such a finding was explained by the fact that resistant mosquitoes, which were less irritated by the insecticide, remained longer on the nets before finally receiving sufficient lethal doses by tarsal contact. ${ }^{16}$ This low irritancy may represent a serious risk against personal protection. A recent experimental hut study carried out in Benin has shown that the proportion of blood-fed females exposed to permethrin-impregnated nets was significantly higher in resistant (R) mosquitoes (both in heterozygous [RS] and homozygous [RR] individuals) than in susceptible (S) ones. ${ }^{13}$ Such findings, which need be confirmed with different insecticides and impregnated substrates, already strengthen the need for alternative chemicals and/or vector control strategies to maintain an effective barrier against pyrethroid-resistant mosquitoes. This is even more relevant for insecticide-treated fabrics or clothing that should maintain a fast-acting effect against resistant insects.

Since the number of new insecticides is drastically dwindling, an alternative strategy to maintain the global effectiveness of ITMs in areas of pyrethroid resistance may be the replacement of pyrethroids by other insecticides such as carbamates or organophosphates. ${ }^{17}$ Although carbamate- or organophosphate-impregnated materials have shown efficacy against pyrethroid-resistant mosquitoes, their low excitorepellency allows mosquitoes to remain a sufficient time on the impregnated surface to take a blood meal. ${ }^{11,18-20}$ Such findings may negate their use in textile or fabric impregnations.

To overcome such limitations for personal protection, we propose an alternative concept to maintain the effectiveness of impregnated materials. This consists of associating a synthetic repellent with a non-pyrethroid insecticide to mimic similar or higher features of pyrethroids, especially irritancy, against pyrethroid-resistant mosquitoes. In this study, DEET, which is a classic synthetic repellent used since World War II for personal protection, was combined with propoxur, a carbamate insecticide, which has high insecticidal activity but low irritant properties against insects. ${ }^{21,22}$ The objectives of this study were to compare the intrinsic efficacy of this nonpyrethroid DEET-propoxur mixture with a reference pyrethroid insecticide (deltamethrin), and to search for synergistic 
interactions between these two compounds. Susceptible and $k d r$-resistant strains of Ae. aegypti, an important vector for arboviruses, were used for this study.

\section{MATERIALS AND METHODS}

Mosquitoes. Two laboratory strains of Ae. aegypti were used in this study. The susceptible Bora strain originated in French Polynesia and has no detectable insecticide resistance mechanism. The pyrethroid-resistant strain LHP originated in Vietnam and was already strongly resistant to permethrin when it was collected in the field. This strain has been maintained under constant permethrin selection at each generation and is now homozygous for the $k d r$ gene (mutation L75W). ${ }^{9}$ The resistant and susceptible strains were evaluated every three months for resistance status and the $\mathrm{R}$ genotype.

Insecticides and repellent. Bioassays were made with technical grade propoxur, DEET, and deltamethrin, the latter of which served as a reference for pyrethroids. The active ingredient of deltamethrin ((S)-alpha-cyano-3-phenoxybenzyl(1R,3R)-3-(2,2-dibromovinyl)-2,2-dimethylcyclopropanecarboxylate) had a purity of $91.5 \%$ and contained at least $98 \%$ of the cis isomer. Propoxur (2-isopropoxyphenyl methylcarbamate) had a purity of $98.4 \%$. DEET had a purity of $97 \%$ and contained a minimum of $95 \%$ of the meta isomer, the most effective molecule of DEET.

Substrates and treatment. Tarsal contact tests were conducted using filter paper treated with the technical grade of each insecticide and repellent. Filter papers were treated following a World Health Organization (WHO) protocol using acetone solutions of insecticide and silicone oil as the carrier. ${ }^{23}$ The impregnation was done by dripping evenly onto the paper $2 \mathrm{~mL}$ of technical grade substance dissolved in acetone and silicone oil. The paper was dried for 12 hours before the test.

Tarsal contact with treated filter paper. The knockdown effect and mortality resulting from tarsal contact with treated filter paper were measured using WHO test kits against adult mosquitoes. ${ }^{23}$ Concentrations were expressed in weight per weight percentage of active ingredient in silicone oil. Batches of 25 non-blood-fed female mosquitoes (2-5 days old) were introduced into holding tubes and maintained for 60 minutes at $27 \pm 2^{\circ} \mathrm{C}$ at a relative humidity of $80 \pm 10 \%$. They were then transferred into exposure tubes and placed vertically for 60 minutes under subdued light. Since pyrethroids are fast-acting insecticides, the number of knocked-down mosquitoes at the bottom of the tubes was recorded every 10 minutes. Mortality was recorded 24 hours after exposure and corrected by the formula of Abbott ${ }^{24}$ if necessary. Data were analyzed by the log-probit method of Finney ${ }^{25}$ using Probit software. ${ }^{26}$ Times after which $50 \%$ and $95 \%$ of mosquitoes were knocked down $\left(\mathrm{KDT}_{50}\right.$ and $\mathrm{KDT}_{95}$, respectively) and their 95\% confidence intervals were estimated with Probit software. Each solution was tested four times and each test was repeated three times with different insect batches to take into account inter-test variability.

Irritability tests. Non-blood-fed female mosquitoes (2-5 days old) were individually introduced into plastic cones fitted with treated filter paper. After exposure 60 seconds, the time elapsed between the first landing and the next take off of the mosquito was recorded as the time for first take off. ${ }^{27}$ Mosquitoes that did not take off at least once during a period of 256 seconds were discarded. For each test, 50 mosquitoes were tested individually. A simple program using the internal clock of a laptop computer has been developed in our laboratory in France to conduct this test and analyze the data. Mosquitoes were grouped by classes of first take off time and cumulative frequencies were used to calculate the time for which $50 \%$ and $95 \%$ of the mosquitoes take off $\left(\mathrm{FT}_{50}\right.$ and $\mathrm{FT}_{95}$, respectively) using Probit software. Fairly constant subdued lighting and air temperature $\left(28 \pm 2^{\circ} \mathrm{C}\right)$ were maintained during the test according to Hodjati and Curtis. ${ }^{28}$

Experimental design. Lethal concentrations of propoxur that induced $30 \%$ mortality $\left(\mathrm{LC}_{30}\right)$ were first determined for each strain of Ae. aegypti to allow better detection of synergistic interactions with DEET. The maximum irritant concentration of DEET was then determined on the susceptible strain. Therefore, the efficacy of DEET-propoxur mixtures, in terms of mortality, knockdown effect and irritancy, was compared with deltamethrin at the $\mathrm{LC}_{100}$ (chosen as a pyrethroid reference concentration). To detect any synergism between DEET and propoxur, we compared the results observed with the DEET-propoxur mixture with those theoretically expected in the absence of any interaction (uncorrelated joint action) between the two compounds. ${ }^{29}$ The expected mortality was calculated by multiplying the survival rates of each compound tested separately and subtracting the result from $100 \%$.

In the same way, the expected KDT and FT for the mixture was calculated by multiplying the percentage of mosquitoes that were not knocked down (air-landed mosquitoes) at each time and subtracting the results from $100 \%$. Synergism occurred when the observed results were significantly higher than the expected one. Conversely, when the observed results were significantly lower than the expected one, there was antagonism.

Statistical analysis. Mortality rates for DEET and propoxur alone and combined were compared with Yates' corrected chi-square test at $0.05 \%$ level of significance. The differences between two $\mathrm{KDT}_{50-95}$ and two $\mathrm{FT}_{50-95}$ values were considered significant if their $95 \%$ confidence intervals did not overlap.

\section{RESULTS}

Preliminary data. The maximum irritant concentration of $1 \%$ DEET induced no mortality and no knockdown effect (Tables 1 and 2). The $\mathrm{LC}_{30} \mathrm{~s}$ of propoxur were $0.02 \%$ and $0.01 \%$ for the Bora and LHP strains, respectively. At this concentration, propoxur induced no knockdown effect and only low irritancy against both mosquito strains (Tables 2 and 3). The $\mathrm{LC}_{100}$ of deltamethrin was estimated to be $0.014 \%$ for the Bora strain. The DEET-propoxur mixtures tested on mosquitoes were $0.02 \%$ propoxur plus $1 \%$ DEET for the Bora strain and $0.01 \%$ propoxur plus $1 \%$ DEET for the LHP strain. All results (mortality, knockdown effect, and irritancy) obtained with each insecticide and repellent, alone or in mixture, are summarized in Tables 1, 2 and 3.

Comparative efficacy between deltamethrin and the DEET-propoxur mixture. The mortality rate of the Bora strain $(100 \%)$ when tested with deltamethrin did not differ significantly from that with DEET-propoxur mixture (96\%) $\left(\chi^{2}=2.30\right.$, degrees of freedom $\left.[\mathrm{df}]=1, P=0.13\right)($ Table 1$)$, but the knockdown effect was significantly higher than with 
TABLE 1

Mortality at 24 hours of susceptible (Bora) and kdr-resistant (LHP) Aedes aegypti mosquitoes exposed for one hour to papers impregnated with deltamethrin, propoxur, and DEET, separate or combined*

\begin{tabular}{|c|c|c|c|c|c|}
\hline & & & ecticida & & \\
\hline & & Dose, $\%$ & No. & $\%$ mortality & $\chi^{2}(P)$ \\
\hline Ae. aegypti (Bora) & Control & - & 300 & No effect & - \\
\hline & Propoxur $\mathrm{LC}_{30}$ & 0.02 & 300 & 34.0 & - \\
\hline & DEET & 1 & 300 & No effect & - \\
\hline & Mixture (observed) & $0.02+1$ & 300 & 96.0 & $\begin{array}{c}81.78 \dagger \\
(<0.0001)\end{array}$ \\
\hline & Mixture (expected) & - & - & 34.0 & - \\
\hline & Deltaméthrine $\mathrm{LC}_{100}$ & 0.014 & 300 & 100.0 & $\begin{array}{c}2.30 \ddagger \\
(0.1297)\end{array}$ \\
\hline Ae. aegypti (LHP) & Control & - & 300 & No effect & - \\
\hline & Propoxur $\mathrm{LC}_{30}$ & 0.01 & 275 & 34.5 & - \\
\hline & DEET & 1 & 300 & No effect & - \\
\hline & Mixture (observed) & $0.01+1$ & 300 & 94.6 & $\begin{array}{c}76.51 \dagger \\
(<0.0001)\end{array}$ \\
\hline & Mixture (expected) & - & - & 34.5 & - \\
\hline & Deltamethrin $\mathrm{LC}^{100}$ & 0.014 & 300 & 9.3 & $\begin{array}{l}144.73 \ddagger \\
(<0.00001)\end{array}$ \\
\hline
\end{tabular}

$* \mathrm{Kdr}=$ knock down resistance; DEET $=\mathrm{N}, \mathrm{N}$-diethyl-toluamide; LC $=$ lethal concentration.

$\dagger$ Chi square and its propability between expected and observed mortalities.

$\doteqdot$ Chi square and its propability between deltamethrin and mixture-induced mortalities.

the DEET-propoxur mixture (both at the $\mathrm{KDT}_{50}$ and $\mathrm{KDT}_{95}$ levels) (Table 2). Irritancy of deltamethrin was greater than that of the DEET-propoxur mixture at the $\mathrm{FT}_{50}$ level, but not significantly different at the $\mathrm{FT}_{95}$ level (Table 3).

The mortality rate of the LHP strain when tested with deltamethrin was fairly low (9\%), but remained high (94\%) with the DEET-propoxur mixture $\left(\chi^{2}=144.73\right.$, df $=1, P<$ 0.0001 ) (Table 1). In addition, the knockdown effect of deltamethrin was not observed in the LHP strain, but was high in the Bora strain (Table 2). The irritant properties of deltamethrin and the DEET-propoxur mixture did not differ significantly from each other at both the $\mathrm{FT}_{50}$ and $\mathrm{FT}_{95}$ levels (confidence intervals overlapped) (Table 3).

Interaction between DEET and propoxur. The DEETpropoxur mixture showed a significantly higher mortality rate (96\%) in the Bora strain than expected (34\%) when testing the hypothesis of an uncorrelated joint action of the two compounds $\left(\chi^{2}=81.78\right.$; df $\left.=1, P<0.0001\right)$ (Table 1$)$. Such results indicate a strong synergism between propoxur and DEET. Moreover, the existence of a knockdown effect with the DEET-propoxur mixture also provided evidence for a striking synergism between these two compounds since DEET and propoxur tested separately did not induce any knockdown effect (Table 2). However, irritancy of the DEET-propoxur mixture was not significantly different from that theoretically expected, indicating an additive effect for this parameter (Table 3).

A synergistic interaction was also observed between DEET and propoxur in the LHP strain for both the mortality rate (94.5\% versus $34.5 \% ; \chi^{2}=76.51$, df $=1, P<0.0001$ ) (Table 1) and the knockdown effect $\left(\mathrm{KDT}_{50}=41.5\right.$ minutes) (Table 2). Conversely, irritancy of the DEET-propoxur mixture was significantly lower than that theoretically expected, indicating an antagonistic interaction between these two compounds (confidence intervals did not overlap) (Table 3 ).

\section{DISCUSSION}

The combination of propoxur (at the $\mathrm{LC}_{30}$ ) and DEET (at a sub-lethal dose) showed irritant properties as high as del-

TABLE 2

Knock-down times $\left(\mathrm{KDt}_{50}\right.$ and $\left.\mathrm{KDt}_{95}\right)$ of susceptible (Bora) and kdr-resistant (LHP) Aedes aegypti mosquitoes exposed for one hour to papers impregnated with deltamethrin, propoxur, and DEET, separate or combined*

\begin{tabular}{|c|c|c|c|c|c|c|c|}
\hline & & \multicolumn{6}{|c|}{ Knock-down effect } \\
\hline & & Dose, $\%$ & No. & $\mathrm{Kdt}_{50}(\min )$ & $95 \% \mathrm{CI}$ & $\mathrm{Kdt}_{95}(\mathrm{~min})$ & $95 \% \mathrm{CI}$ \\
\hline \multirow[t]{6}{*}{ Ae. aegypti (Bora) } & Control & - & 300 & No effect & - & No effect & - \\
\hline & Propoxur $\mathrm{LC}_{30}$ & 0.02 & 300 & No effect & - & No effect & - \\
\hline & DEET & 1 & 300 & No effect & - & No effect & - \\
\hline & Mixture (observed) & $0.02+1$ & 300 & 36.6 & $35.7-37.4$ & 54.8 & $52.9-57.0$ \\
\hline & Mixture (expected) & - & - & - & - & - & - \\
\hline & Deltamethrin $\mathrm{LC}_{100}$ & 0.014 & 300 & 23.8 & $21.6-26.2$ & 38.3 & $32.5-45.1$ \\
\hline \multirow[t]{6}{*}{ Ae. aegypti (LHP) } & Control & - & 300 & No effect & - & No effect & - \\
\hline & Propoxur $\mathrm{LC}_{30}$ & 0.01 & 300 & No effect & - & No effect & - \\
\hline & DEET & 1 & 300 & No effect & - & No effect & - \\
\hline & Mixture (observed) & $0.01+1$ & 300 & 41.5 & $40.6-42.4$ & 60.1 & $58.1-62.5$ \\
\hline & Mixture (expected) & - & - & - & - & - & - \\
\hline & Deltamethrin $\mathrm{LC}_{100}$ & 0.014 & 300 & No effect & - & No effect & - \\
\hline
\end{tabular}


TABLE 3

Time of first take-off $\left(\mathrm{FT}_{50}\right.$ and $\left.\mathrm{FT}_{95}\right)$ of susceptible (Bora) and kdr-resistant (LHP) Aedes aegypti mosquitoes exposed to papers impregnated with deltamethrin, propoxur, and DEET, separate or combined.*

\begin{tabular}{|c|c|c|c|c|c|c|c|}
\hline & & & & & Irritant effect & & \\
\hline & & Dose, \% & No. & $\mathrm{FT}_{50}(\mathrm{sec})$ & $95 \% \mathrm{CI}$ & $\mathrm{FT}_{95}(\mathrm{sec})$ & $95 \% \mathrm{CI}$ \\
\hline Ae. aegypti (Bora) & Control & - & 163 & 251 & $188.8-363.9$ & $6,256.1$ & $3,122.2-16,269.7$ \\
\hline & Propoxur $\mathrm{LC}_{30}$ & 0.02 & 150 & 133.9 & $108.8-172.3$ & $2,508.1$ & $1,486.7-4,993.3$ \\
\hline & DEET & 1 & 150 & 24.2 & $21.9-26.8$ & 128.2 & $107.6-157.4$ \\
\hline & Mixture (observed) & $0.02+1$ & 150 & 21.5 & $18.7-24.6$ & 88.9 & $69.7-114.7$ \\
\hline & Mixture (expected) & - & - & 19.2 & $17.0-21.7$ & 96.4 & $78.7-123.3$ \\
\hline & Deltamethrin $\mathrm{LC}_{100}$ & 0.014 & 150 & 15.4 & $13.9-17.1$ & 86.9 & $72.9-106.8$ \\
\hline A. aegypti (LHP) & Control & - & 150 & 81.2 & $63.8-104.0$ & 739.3 & $379.0-1,501.8$ \\
\hline & Propoxur $\mathrm{LC}_{30}$ & 0.01 & 153 & 62.5 & $54.0-73.6$ & 856.9 & $607.3-1,308.0$ \\
\hline & DEET & 1 & 150 & 23.6 & $19.3-28.9$ & 172.1 & $116.1-257.8$ \\
\hline & Mixture (observed) & $0.01+1$ & 152 & 23.6 & $21.2-26.2$ & 159.3 & $133.2-195.8$ \\
\hline & Mixture (expected) & - & - & 15.8 & $14.0-17.9$ & 101.6 & $81.1-133.2$ \\
\hline & Deltamethrin $\mathrm{LC}_{100}$ & 0.014 & 152 & 24.1 & $21.5-27.0$ & 183.2 & $148.0-236.1$ \\
\hline
\end{tabular}

$* \mathrm{FT}_{50}=50 \%$ take-off time; $\mathrm{FT}_{95}=95 \%$ take-off time; DEET $=\mathrm{N}, \mathrm{N}$-diethyl-toluamide; $\mathrm{CI}=$ confidence interval; $\mathrm{LC}=$ lethal concentration.

tamethrin (at the $\mathrm{LC}_{100}$ ) against both Bora and LHP mosquito strains, although irritancy was slightly lower against LHP mosquitoes. In the LHP strain, the decrease in irritancy with deltamethrin might be due to the presence of the $k d r$ mutation, although it probably results from a more complex phenomenon for the DEET-propoxur combination. It is likely that the massive knockdown effect observed with the DEET-propoxur mixture disrupted the time for first take off of mosquitoes, since knocked-down mosquitoes were unable to fly. This phenomenon probably explained the antagonistic interaction in irritancy observed between propoxur and DEET in the LHP strain.

A strong synergism was reported between an insecticide and a repellent. The level of synergy detected with this nonpyrethroid DEET-propoxur mixture was higher than those previously observed between pyrethroids and carbamates (e.g., propoxur) or organophosphates against Anopheles mosquitoes. ${ }^{30,31}$ The most intriguing result was the manifestation of a knockdown effect induced by compounds other than pyrethroids, especially against LHP mosquitoes. Such findings are of practical importance since the knockdown effect is an essential characteristic in personal protection against mosquito bites.

The physiologic mechanisms responsible for synergistic interactions between DEET and propoxur remain unclear. The mode of action of carbamates is well known (inhibition of acetylcholinesterase), but that of DEET has not been elucidated. ${ }^{32}$ Davis proposed several assumptions to explain the effect of DEET in insects ${ }^{33}: 1$ ) inhibition of an attraction signal; 2) inversion of attraction signal perception for an irritant message; 3) activation of a receptor system that could mediate a competing or inappropriate behavior pattern; 4) activation of a noxious odor receptor; and 5) activation of different receptors that could mediate various behavior patterns, indicating that repellents are interfering with the sensory information system.

In this study, we used filter papers without any vertebrate host. DEET acts not only by inducing a disruption of an attraction signal, but also by generating a physiologic perturbation in mosquitoes. Indeed, preliminary bioassays have shown that a DEET concentration range of $5-10 \%$ induced mortality and a knockdown effect as great as pyrethroids (Pennetier C, unpublished data). In addition, electrophysi- ologic tests with dorsal unpaired median neurons of American cockroach (Periplaneta americana) showed that DEET induced a strong neurotoxic effect (Lapied B, unpublished data). As previously observed by Corbel and others ${ }^{34}$ with insecticide combinations, synergism between DEET and propoxur may be the result of a general physiologic disruption involving different target sites in the central nervous system. Further investigations are now in progress to determine precisely the mode of action of DEET alone and in combination with other compounds on insect physiology.

Another possible explanation for the observed synergism is detoxification by enzymes in insects. One component of the DEET-propoxur mixture may interfere with the detoxification of the other, thereby increasing the toxicity of the two compounds. ${ }^{35,36}$ For example, synergism between organophosphates and pyrethroids was caused by sequestration of organophosphates by esterases, which prevented the degradation of pyrethroids. ${ }^{37}$ Although DEET does not share ester bonds, other enzymes such as oxidases have been shown to be involved in its detoxification and could therefore play a role in synergism. ${ }^{38-40}$

In conclusion, a DEET-propoxur mixture may be a new promising tool for vector control because pyrethroid resistance is now widely prevalent in mosquitoes worldwide, especially in Africa. The control of Ae. aegypti, which is based mainly on pyrethroid sprays or impregnated materials, is being threatened by pyrethroid resistance. A combination of DEET and propoxur (or others carbamates) may improve personal protection against $k d r$-resistant mosquitoes and contribute to a better management of pyrethroid resistance. Another use for such a mixture stems from the fact that the Ace. $1^{R}$ mutation (G119S), which confers cross-resistance to organophosphates and carbamates, has never been observed in $A e$. aegypti, and is unlikely to appear since it requires a double mutation. ${ }^{41,42}$ In contrast to Ae. aegypti, the Ace. $1^{R}$ mutation has been found in An. gambiae, the main malaria vector in Africa and in $C x$. quinquefasciatus, the main urban mosquito in tropical areas. ${ }^{43}$ It will be interesting to investigate the impact of the Ace. $1^{R}$ gene on the efficacy of this DEET-propoxur mixture. Since DEET is a volatile compound, there is an urgent need to search for an adequate formulation that could extend the residual effect of this combination in impregnated materials. Recent investigations in 
the laboratory have shown that efficacy of a DEET-based formulation (Insect Ecran ${ }^{\circledR}$; Osler, Paris, France) persisted for at least 45 days on netting against pyrethroid-resistant $C x$. quinquefasciatus (N'Guessan R, unpublished data). These findings constitute a first step towards an alternative strategy of combating vectors of human diseases.

Received September 24, 2004. Accepted for publication December 13, 2004.

Acknowledgments: We are very grateful to Raphael N'Guessan (London School of Hygiene and Tropical Medicine) for helpful comments and discussions. We also thank Bayer (Leverkusen, Germany), Agrevo (Berkhamsted, United Kingdom), and Sigma-Aldrich (Saint Quentin Fallavier, France) for providing the technical grades of propoxur, deltamethrin, and DEET.

Authors' addresses: Cédric Pennetier and Vincent Corbel, Laboratoire de Lutte contre les Insectes Nuisibles, Institut de Recherche pour le Développement, 911 Avenue Agropolis, BP 64501, 34394 Montpellier cedex 5, France, Telephone: 33-467-04-19-24, Fax: 33467-54-20-44, E-mails: cedric.pennetier@ird.fr and corbel@mpl.ird.fr. Jean-Marc Hougard, Centre Institut de Recherche pour le Développement du Benin, 01 BP 4414 RP, Cotonou, Benin, Telephone: 229-30-03-54, Fax: 229-30-88-60, E-mail: hougard@ird.fr.

\section{REFERENCES}

1. Elliott M, Janes NF, Jeffs KA, Needham PH, Sawicki RM, 1965. New pyrethrin-like esters with high insecticidal activity. Nature 207: 938-940.

2. Elliot M, Janes NF, 1978. Synthetic pyrethroids-a new class of insecticides. Chem Soc Rev 7: 473-505.

3. Zaim M, Aitio A, Nakashima N, 2000. Safety of pyrethroidtreated mosquito nets. Med Vet Entomol 14: 1-5.

4. Lengeler C, 2004. Insecticide-treated bed nets and curtains for preventing malaria. Cochrane Database Syst Rev: CD000363.

5. World Health Organization, 1997. Vector Control: Methods for Use by Individuals and Communities. Geneva: World Health Organization, 52-177.

6. Martinez-Torres D, Foster SP, Field LM, Devonshire AL, Williamson MS, 1999. A sodium channel point mutation is associated with resistance to DDT and pyrethroid insecticides in the peach-potato aphid, Myzus persicae (Sulzer) (Hemiptera: Aphididae). Insect Mol Biol 8: 339-346.

7. Martinez-Torres D, Chandre F, Williamson MS, Darriet F, Berge JB, Devonshire AL, Guillet P, Pasteur N, Pauron D, 1998. Molecular characterization of pyrethroid knockdown resistance (kdr) in the major malaria vector Anopheles gambiae s.s. Insect Mol Biol 7: 179-184.

8. Chandre F, Darriet F, Manguin S, Brengues C, Carnevale P, Guillet P, 1999. Pyrethroid cross resistance spectrum among populations of Anopheles gambiae s.s. from Cotê d'Ivoire. J Am Mosq Control Assoc 15: 53-59.

9. Brengues C, Hawkes NJ, Chandre F, McCarroll L, Duchon S, Guillet P, Manguin S, Morgan JC, Hemingway J, 2003. Pyrethroid and DDT cross-resistance in Aedes aegypti is correlated with novel mutations in the voltage-gated sodium channel gene. Med Vet Entomol 17: 87-94.

10. Hemingway J, Ranson H, 2000. Insecticide resistance in insect vectors of human disease. Annu Rev Entomol 45: 371-391.

11. Kolaczinski JH, Fanello C, Herve JP, Conway DJ, Carnevale P, Curtis CF, 2000. Experimental and molecular genetic analysis of the impact of pyrethroid and non-pyrethroid insecticide impregnated bed-nets for mosquito control in an area of pyrethroid resistance. Bull Entomol Res 90: 125-132.

12. Darriet F, Guillet P, N'Guessan R, Doannio JM, Koffi A, Konan LY, Carnevale P, 1998. Impact of resistance of Anopheles gambiae s.s. to permethrin and deltamethrin on the efficacy of impregnated mosquito nets. Med Trop (Mars) 58-4: 349-354.

13. Corbel V, Chandre F, Brengues C, Akogbeto M, Lardeux F, Hougard JM, Guillet P, 2004. Dosage-dependent effects of permethrin-treated nets on the behaviour of Anopheles gam- biae and the selection of pyrethroid resistance. Malar $J$ 3-1: $22-30$.

14. Darriet F, Guillet P, N'Guessan RN, Doannio JMC, Koffi AA, Konan LY, Carnevale P, 1999. The Impact of Permethrin and Deltamethrin Resistance in Anopheles gambiae s.s. on Efficacy of Insecticide-Treated Mosquito Nets. Geneva: World Health Organization. WHO/VBC/99.1002.

15. Darriet F, N'Guessan R, Koffi AA, Konan L, Doannio JM, Chandre F, Carnevale P, 2000. Impact of pyrethrin resistance on the efficacy of impregnated mosquito nets in the prevention of malaria: results of tests in experimental cases with deltamethrin. Bull Soc Pathol Exot 93-2: 131-134.

16. Chandre F, Darriet F, Duchon S, Finot L, Manguin S, Carnevale P, Guillet P, 2000. Modifications of pyrethroid effects associated with kdr mutation in Anopheles gambiae. Med Vet Entomol 14: 81-88.

17. Curtis CF, Miller JE, Hodjati MH, Kolaczinski JH, Kasumba I, 1998. Can anything be done to maintain the effectiveness of pyrethroid-impregnated bed-nets against malaria vectors? Philos Trans R Soc Lond B Biol Sci 353-1376: 1769-1775.

18. Fanello C, Carneiro I, Ilboudo-Sanogo E, Cuzin-Ouattara N, Badolo A, Curtis CF, 2003. Comparative evaluation of carbosulfan- and permethrin-impregnated curtains for preventing house-entry by the malaria vector Anopheles gambiae in Burkina Faso. Med Vet Entomol 17-3: 333-338.

19. N'Guessan R, Darriet F, Guillet P, Carnevale P, TraoreLamizana M, Corbel V, Koffi AA, Chandre F, 2003. Resistance to carbosulfan in Anopheles gambiae from Ivory Coast, based on reduced sensitivity of acetylcholinesterase. Med Vet Entomol 17-1: 19-25.

20. Curtis CF, Mnzava AE, 2000. Comparison of house spraying and insecticide-treated nets for malaria control. Bull World Health Organ 78-12: 1389-1400.

21. Qiu H, Jun HW, McCall JW, 1998. Pharmacokinetics, formulation, and safety of insect repellent N,N-diethyl-3-methylbenzamide (DEET): a review. J Am Mosq Control Assoc 14-1: 12-27.

22. Curtis CF, Mnzava AE, 2000. Comparison of house spraying and insecticide-treated nets for malaria control. Bull World Health Organ 78-12: 1389-1400.

23. World Health Organization, 1998. Report of WHO Informal Consultation Tests Procedures for Insecticide Resistance Monitoring in Malaria Vectors, Bio-efficacy and Persistence of Insecticides on Treated Surfaces. Geneva: World Health Organization. $\mathrm{WHO} / \mathrm{CDS} / \mathrm{CPC} / \mathrm{MAL} / 98.12$.

24. Abbott WS, 1925. A method of computing the effectiveness of an insecticide. J Econ Entomol 18: 265-267.

25. Finney DJ, 1971. Probit Analysis. Cambridge, United Kingdom: Cambridge University Press.

26. Raymond M, Prato G, Ratsira D, 1997. Probit and Logit Analysis Program Version 2.0. Montpellier, France: Centre National de Scientifique.

27. Mouchet J, Cavalie P, Callies JM, Marticou H, 1961. Irritability with respect to DDT of Anopheles gambiae and A. funestus in northern Cameroon. Riv Malariol 40: 191-217.

28. Hodjati MH, Curtis CF, 1999. Effects of permethrin at different temperatures on pyrethroid-resistant and susceptible strains of Anopheles. Med Vet Entomol 13-4: 415-422.

29. Bliss CI, 1939. The toxicity of poisons applied jointly. Ann Appl Biol 26: 585-615.

30. Corbel V, Darriet F, Chandre F, Hougard JM, 2002. Insecticide mixtures for mosquito net impregnation against malaria vectors. Parasite 9: 255-259.

31. Darriet F, Corbel V, Hougard JM, 2003. Efficacy of mosquito nets treated with a pyrethroid-organophosphorous mixture against Kdr- and Kdr+ malaria vectors (Anopheles gambiae). Parasite 10: 359-362.

32. Eldefrawi AT, Eldefrawi ME, 1976. Identification of a calciumbinding subunit of the acetylcholine receptor. Biochem Biophys Res Commun 70: 1020-1027.

33. Davis EE, 1985. Insect repellents: concepts of their mode of action relative to potential sensory mechanisms in mosquitoes (Diptera: Culicidae). J Med Entomol 22: 237-243.

34. Corbel V, Hue B, Bonnet J, Hougard JM, Lapied B, 2004. Effects of pyrethroid and carbamate combinations on insect synaptic 
transmission. Proceedings of IX European Multicolloquium of Parasitology. Valencia, Spain. July 18-23, 2004

35. Corbett JR, 1974. The Biochemical Mode of Action of Pesticides. New York: Academic Press.

36. Wilkinson CF, 1976. Insecticide interactions. Wilkinson $\mathrm{CF}$, ed. Insecticide Biochemistry and Physiology. New York: Plenum Press, 605-647.

37. Gunning RV, Moores GD, Devonshire AL, 1999. Esterase inhibitors synergise the toxicity of pyrethroids in Australian $\mathrm{He}$ licoperva armigera (Lepidoptera: Noctuidae). Pest Biochem Physiol 63: 50-62.

38. Constantino L, Rosa E, Iley J, 1992. The microsomal demethylation of N,N-dimethylbenzamides. Substituent and kinetic deuterium isotope effects. Biochem Pharmacol 44: 651-658.

39. Constantino L, Iley J, 1999. Microsomal metabolism of N,N- diethyl-m-toluamide (DEET, DET): the extended network of metabolites. Xenobiotica 29: 409-416.

40. Iley J, Constantino L, 1993. The microsomal dealkylation of N,Ndialkylbenzamides. Biochem Pharmacol 47: 275-280.

41. Weill M, Malcolm C, Chandre F, Mogensen K, Berthomieu A, Marquine M, Raymond M, 2004. The unique mutation in ace-1 giving high insecticide resistance is easily detectable in mosquito vectors. Insect Mol Biol 13: 1-7.

42. Weill M, Berthomieu A, Berticat C, Lutfalla G, Negre V, Pasteur N, Philips A, Leonetti JP, Fort P, Raymond M, 2004. Insecticide resistance: a silent base prediction. Curr Biol 14-14: R552R553.

43. Weill M, Lutfalla G, Mogensen K, Chandre F, Berthomieu A, Berticat C, Pasteur N, Philips A, Fort P, Raymond M, 2003. Comparative genomics: Insecticide resistance in mosquito vectors. Nature 423-6936: 136-137. 